NATIONAL LABORATORY

MANAGED BY UT-BATTELLE

FOR THE DEPARTMENT OF ENERGY

\title{
Neutronic analysis of candidate accident-tolerant iron alloy cladding concepts
}

\section{March 2013}

N. M. George

K. A. Terrani

J. J. Powers

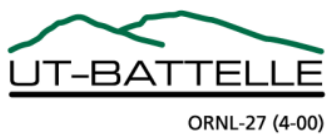




\title{
DOCUMENT AVAILABILITY
}

Reports produced after January 1, 1996, are generally available free via the U.S. Department of Energy (DOE) Information Bridge.

Web site http://www.osti.gov/bridge

Reports produced before January 1, 1996, may be purchased by members of the public from the following source.

\author{
National Technical Information Service \\ 5285 Port Royal Road \\ Springfield, VA 22161 \\ Telephone 703-605-6000 (1-800-553-6847) \\ TDD 703-487-4639 \\ Fax 703-605-6900 \\ E-mail info@ntis.gov \\ Web site http://www.ntis.gov/support/ordernowabout.htm
}

Reports are available to DOE employees, DOE contractors, Energy Technology Data Exchange (ETDE) representatives, and International Nuclear Information System (INIS) representatives from the following source.

Office of Scientific and Technical Information

P.O. Box 62

Oak Ridge, TN 37831

Telephone 865-576-8401

Fax 865-576-5728

E-mail reports@osti.gov

Web site http://www.osti.gov/contact.html

This report was prepared as an account of work sponsored by an agency of the United States Government. Neither the United States Government nor any agency thereof, nor any of their employees, makes any warranty, express or implied, or assumes any legal liability or responsibility for the accuracy, completeness, or usefulness of any information, apparatus, product, or process disclosed, or represents that its use would not infringe privately owned rights. Reference herein to any specific commercial product, process, or service by trade name, trademark, manufacturer, or otherwise, does not necessarily constitute or imply its endorsement, recommendation, or favoring by the United States Government or any agency thereof. The views and opinions of authors expressed herein do not necessarily state or reflect those of the United States Government or any agency thereof. 


\title{
NEUTRONIC ANALYSIS OF CANDIDATE ACCIDENT-TOLERANT IRON ALLOY CLADDING CONCEPTS
}

\author{
N. M. George \\ K. A. Terrani \\ J. J. Powers
}

Date Published: March 2013

Prepared by

OAK RIDGE NATIONAL LABORATORY

Oak Ridge, Tennessee 37831-6283

managed by

UT-BATTELLE, LLC

for the

U.S. DEPARTMENT OF ENERGY

under contract DE-AC05-00OR22725 
Intentionally left blank 


\section{CONTENTS}

\section{Page}

CONTENTS …

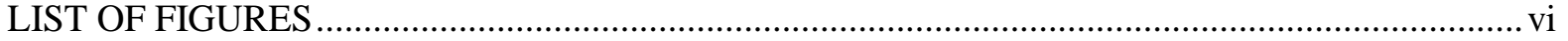

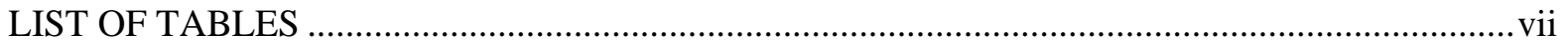

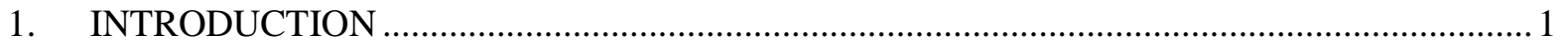

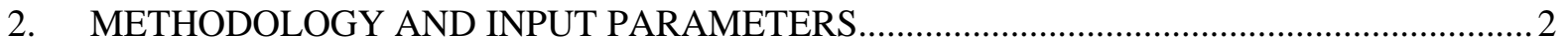

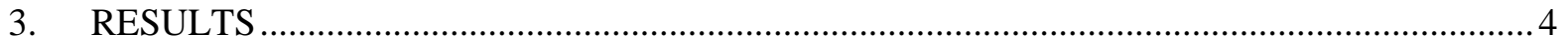

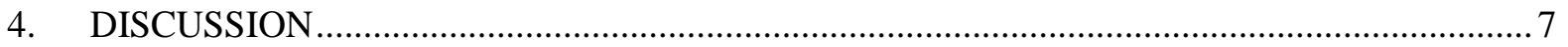

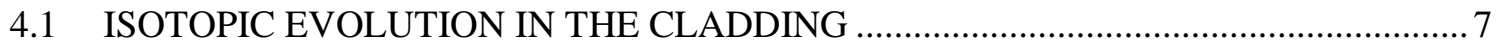

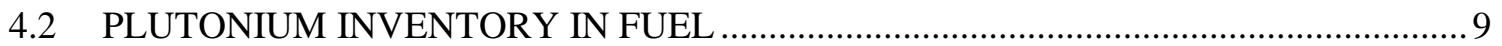

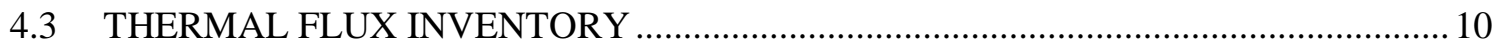

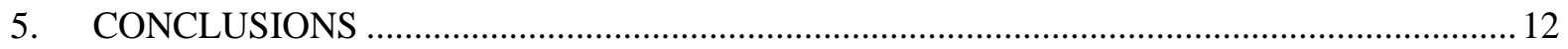

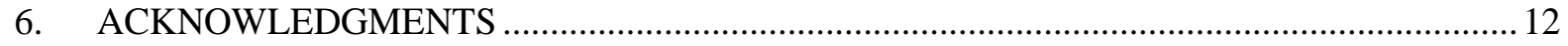

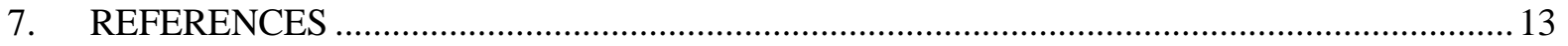




\section{LIST OF FIGURES}

\section{Page}

Figure 1. Infinite multiplication factor vs. EFPD for various cladding materials in standard PWR $17 \times 17$ rod geometry. .4

Figure 2. $\Delta \mathrm{k}_{\text {inf }}$ from Zircaloy-4 clad fuel vs. EFPD for various cladding materials. ............................5

Figure 3. Evolution in isotopic inventory in Zircaloy-4 cladding during fuel lifetime.........................7

Figure 4. Evolution in isotopic inventory in 304SS cladding during fuel lifetime. ............................

Figure 5. Evolution in isotopic inventory in 310SS cladding during fuel lifetime. ............................ 8

Figure 6. Evolution in isotopic inventory in FeCrAl cladding during fuel lifetime.............................9

Figure 7. Evolution in plutonium inventory during lifetime with various cladding materials.............10

Figure 8. Average scalar flux of various cladding material designs with respect to energy................11 


\section{LIST OF TABLES}

\section{Page}

Table 1. Cladding compositions used for fuel reactivity calculations............................................. 2

Table 2. Density and average thermal neutron absorption cross section for various cladding

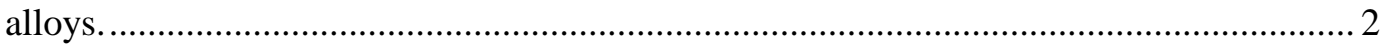

Table 3. Various rod geometries used during reactivity calculations................................................. 3

Table 4. Distribution in population and power per fuel cycle batch in typical Westinghouse

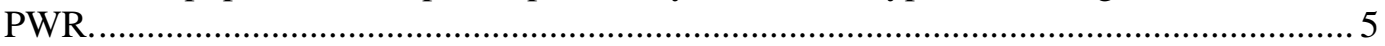

Table 5. Cycle reactivity difference for alternate fuel cladding concepts from the reference

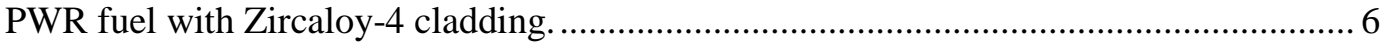





\section{INTRODUCTION}

The outcome of a severe accident scenario in a light water reactor (LWR) is largely dominated by the type and availability of safety systems in place and the sequence of events. In loss of coolant scenarios, decay heat coupled with poor heat conductance in steam drives up the core temperature. The onset of physical and chemical degradation phenomena takes place at temperatures above approximately $800^{\circ} \mathrm{C}$, where fuel rod burst is experienced [1]. As the core temperature increases, detrimental interaction between core constituents and steam oxidation exacerbate core degradation processes. This is done by compromising coolability in the core and deposition of a large amount of enthalpy (oxidation) in addition to what is deposited by decay heat [2]. Given this understanding, an international effort is under way to examine alternate fuel cladding concepts that exhibit slower oxidation kinetics in high-temperature steam environments when compared to zirconium alloys [3-5].

The purpose of this document is to provide preliminary insight with regards to the neutronic aspects of utilization of alternate cladding concepts in LWR cores. This is deemed necessary to guide the broader fuel development and qualification efforts. Though many alternate cladding concepts are now being examined as candidate accident-tolerant fuel cladding concepts, this paper reports results for certain ironbased cladding materials. The results are compared with the neutronic performance of the reference zirconium alloy fuel pins. At this time, the scope of the study has been limited to single pins in a pressurized water reactor (PWR). 


\section{METHODOLOGY AND INPUT PARAMETERS}

A set of simplified reactivity calculations is performed using SCALE/TRITON from the SCALE 6.1 software system package to model a single fuel rod [6-8]. The CENTRM module from SCALE was used to determine cross-section approximations in one dimension; the continuous energy spectrum was flux weighted in order to produce resonance-shielded multi-group cross-section data. The energy spectrum was thus collapsed to 238 groups using ENDF/B-VII continuous energy nuclear data. SCALE/TRITON couples the two-dimensional discrete-ordinates radiation transport code NEWT with ORIGEN-S for isotopic decay and depletion calculations; this system is capable of performing activation calculations in the clad as well as depletion calculations in the fuel. ORIGEN-S takes the neutron cross sections and fluxes from the transport calculations and generates time-dependent isotopic concentrations as a function of burnup. After each depletion step, the new isotopics generated from ORIGEN-S are fed back into the transport calculation and the process is repeated until the depletion cycle is complete. Clad composition changes due to neutron absorption in the cladding were accounted for in these calculations.

Table 1 reports the alternate cladding materials examined in this study along with their detailed elemental composition. This list includes a baseline zirconium alloy (Zircaloy-4) as well as the historic 304 austenitic stainless steel. Grade 310 austenitic stainless steel and a generic and a commercial variant (APMT) [9] of a ferritic iron-chromium-aluminum (Fe-Cr-Al) alloy are also examined.

Table 1. Cladding compositions used for fuel reactivity calculations

\begin{tabular}{|c|c|c|c|c|c|c|c|c|c|c|c|c|}
\hline Material & & $\mathrm{Fe}$ & $\mathrm{Cr}$ & Al & $\mathrm{Zr}$ & $\mathrm{Ni}$ & Sn & Mn & Mo & $Y$ & $\mathrm{Si}$ & Hf \\
\hline Zircaloy & \multirow{5}{*}{$\frac{0}{0}$} & 0.15 & 0.1 & & 98.75 & & 1.5 & & & & & \\
\hline $304 S S$ & & 71.35 & 18.9 & & 0 & 8.35 & & 0.7 & 0.27 & & 0.42 & \\
\hline $310 S S$ & & 52.5 & 25.2 & & 0 & 19.5 & & 1.9 & 0.13 & & 0.7 & \\
\hline FeCrAl & & 75 & 20 & 5 & 0 & & & & 0 & & 0 & \\
\hline APMT & & 69.79 & 21.6 & 4.9 & 0.1 & & & & 2.8 & 0.12 & 0.53 & 0.16 \\
\hline Zircaloy & \multirow{5}{*}{$\stackrel{\stackrel{0}{\sigma}}{\stackrel{0}{\sigma}}$} & 0.24 & 0.17 & & 98.43 & & 1.15 & & & & & \\
\hline $304 S S$ & & 70.44 & 20.04 & & & 7.84 & & 0.7 & 0.16 & & 0.82 & \\
\hline $310 S S$ & & 51.72 & 26.66 & & & 18.27 & & 1.9 & 0.07 & & 1.37 & \\
\hline FeCrAl & & 70.2 & 20.11 & 9.69 & & & & & & & & \\
\hline APMT & & 65.84 & 21.89 & 9.57 & 0.06 & & & & 1.54 & 0.07 & 0.99 & 0.05 \\
\hline
\end{tabular}

Table 2. Density and average thermal neutron absorption cross section for various cladding alloys

\begin{tabular}{lcc}
\hline Material & Density $\left[\mathrm{g} / \mathrm{cm}^{\mathbf{3}}\right]$ & Average thermal neutron absorption cross section $[\mathrm{barns}]$ \\
\hline Zircaloy & 6.56 & 0.20 \\
304SS & 7.9 & 2.86 \\
310SS & 8.03 & 3.21 \\
FeCrAl & 7.1 & 2.43 \\
APMT & 7.3 & 2.47 \\
\hline
\end{tabular}


For reactivity calculations, a number of fuel rod geometries were considered. The reference case chosen was from a standard PWR $17 \times 17$ fuel bundle [10] with $4.9 \%$ enriched urania $\left(\mathrm{UO}_{2}\right)$ pellets. The density of the $\mathrm{UO}_{2}$ pellet is set at $96 \%$ of theoretical density, yielding $10.47 \mathrm{~g} / \mathrm{cm}^{3}$. The pitch-to-diameter ratio (P/D) for all the cases is fixed at 1.326. Surrounding the fuel rod is borated water consisting of $0.723 \mathrm{~g} / \mathrm{cc}$ of $\mathrm{H}_{2} \mathrm{O}$ and boron. The water contains $630 \mathrm{ppm}$ boron which represents the average concentration throughout a PWR cycle. The $\mathrm{UO}_{2}$ fuel pellet was modeled at $900 \mathrm{~K}$ while the cladding and moderator temperatures were set to $600 \mathrm{~K}$ and $580 \mathrm{~K}$ respectively. Table 3 reports the various geometries used during the reactivity calculation where Case 1 is the reference case. The other cases are analyzed in order to increase heavy metal and fissile loading in the core by either increasing the pellet diameter (at the expense of reducing cladding thickness) or uranium enrichment, respectively.

Table 3. Various rod geometries used during reactivity calculations

\begin{tabular}{ccccccc}
\hline Case \# & Pellet OD [mm] & Gap [ $\mu \mathrm{m}]$ & Clad ID [mm] & Clad OD [mm] & Clad Thickness $[\mu \mathrm{m}]$ & U enrichment \\
\hline 1 (ref) & 8.1915 & 82.55 & 8.3566 & 9.4996 & 571.5 & $4.9 \%$ \\
2 & 8.3345 & 82.55 & 8.4996 & 9.4996 & 500 & $4.9 \%$ \\
3 & 8.5345 & 82.55 & 8.6996 & 9.4996 & 400 & $4.9 \%$ \\
4 & 8.7345 & 82.55 & 8.8996 & 9.4996 & 300 & $4.9 \%$ \\
5 & 8.1915 & 82.55 & 8.3566 & 9.4996 & 571.5 & $5.5 \%$ \\
6 & 8.1915 & 82.55 & 8.3566 & 9.4996 & 571.5 & $6.0 \%$ \\
7 & 8.1915 & 82.55 & 8.3566 & 9.4996 & 571.5 & $6.5 \%$ \\
8 & 8.1915 & 82.55 & 8.3566 & 9.4996 & 571.5 & $7.0 \%$ \\
\hline
\end{tabular}




\section{RESULTS}

Reactivity as a function of effective full power days (EFPD) in fuel rods with the standard PWR $17 \times 17$ geometry and various cladding materials is shown in Figure 1. The neutronic penalty associated with utilization of alternate cladding materials due to the larger neutron absorption cross section in these materials is more easily seen in Figure 2, where the difference in the infinite multiplication factor from the reference case is shown.

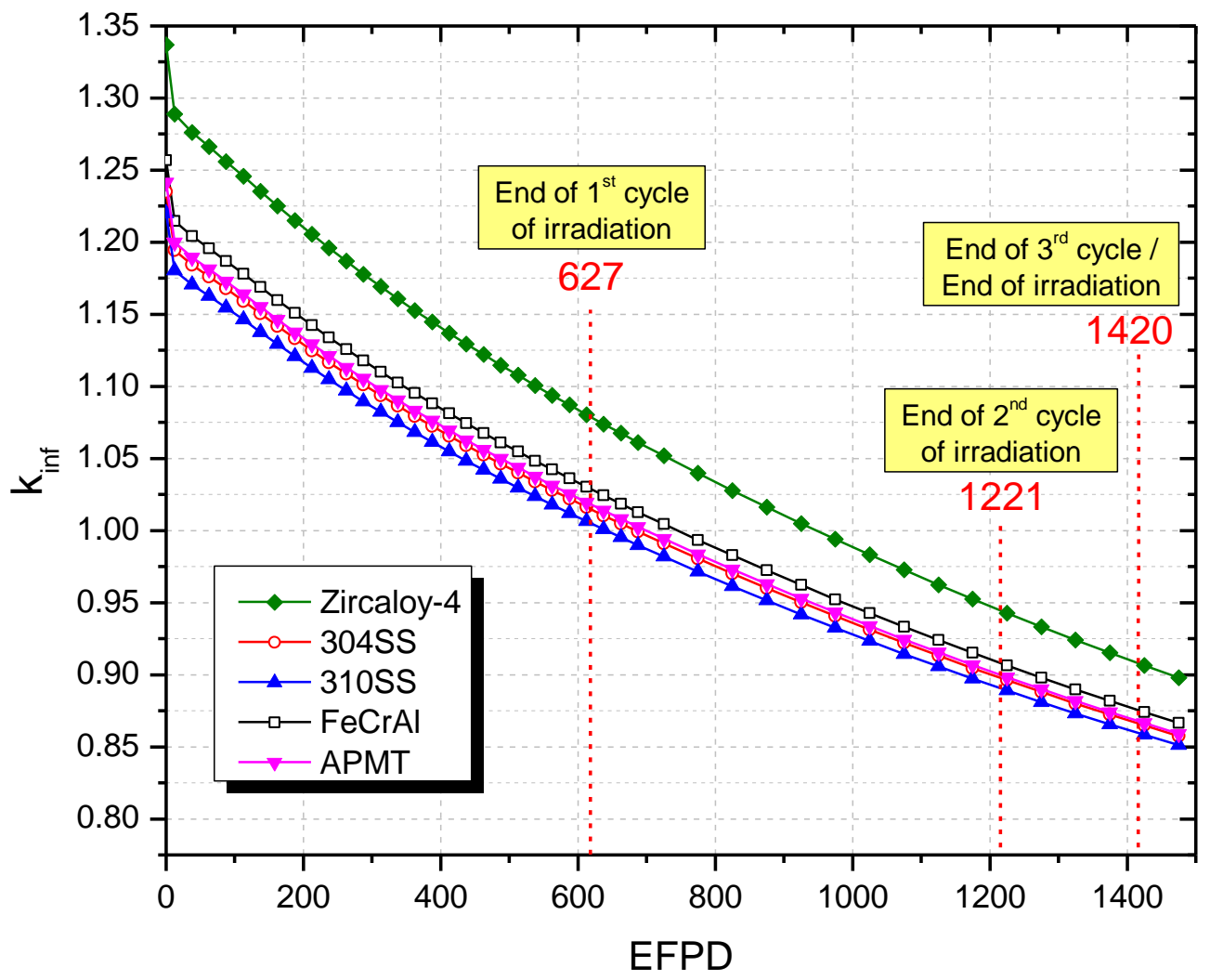

Figure 1. Infinite multiplication factor vs. EFPD for various cladding materials in standard PWR 17×17 rod geometry. 


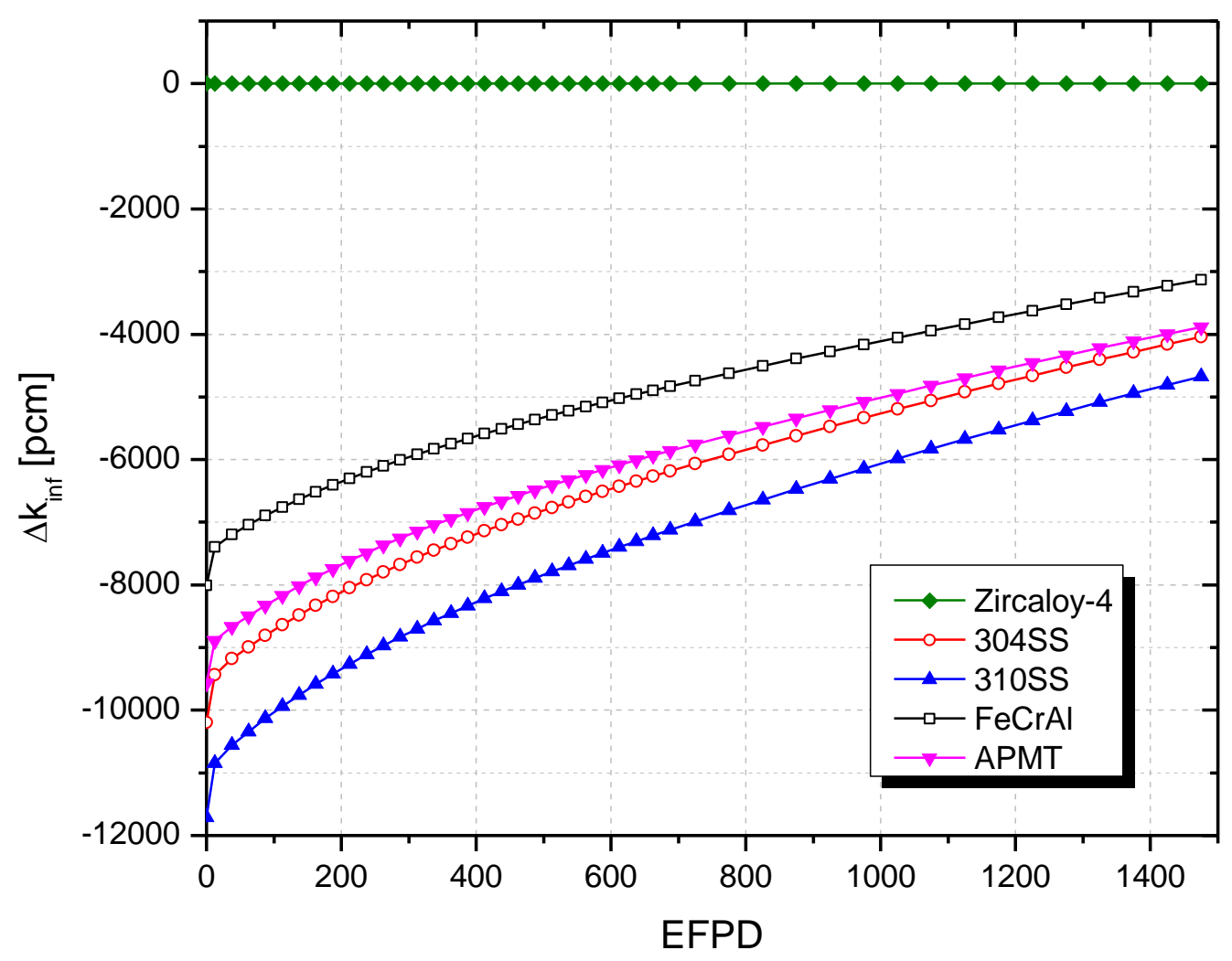

Figure $2 . \Delta \mathrm{k}_{\text {inf }}$ from Zircaloy-4 clad fuel vs. EFPD for various cladding materials.

The drop in reactivity for alternate cladding materials corresponds to a significant reduction in operational cycle length. To enhance the reactivity and increase the cycle length, modified bundle geometries or increased enrichment in the fuel are necessary. Accordingly, fuel rod designs conforming to Cases 2-8 in Table 3 are considered for alternate cladding concepts.

An analytical method was applied to the single-pin depletion results in order to approximate a multi-batch loading scheme. Table 4 provides batch-specific powers for a typical Westinghouse PWR; these parameters were used to determine the effective EFPD for a given batch of fuel at the end of each of the three cycles of irradiation, which are also given in the table. The vertical lines in Figure 1 denote the cycle duration for each assumed batch.

Table 4. Distribution in population and power per fuel cycle batch in typical Westinghouse PWR

\begin{tabular}{ccccc}
\hline Batch & \# Assemblies & $\begin{array}{c}\text { Core Fraction } \\
\text { Vol \% }\end{array}$ & $\begin{array}{c}\text { Relative Assembly } \\
\text { Power }\end{array}$ & $\begin{array}{c}\text { EFPD Achieved by Batch at } \\
\text { End of Each Cycle }\end{array}$ \\
\hline 1 & 73 & $38 \%$ & 1.25 & 627 \\
2 & 68 & $35 \%$ & 1.19 & 1221 \\
3 & 52 & $27 \%$ & 0.40 & 1420 \\
Total & $\mathbf{1 9 3}$ & $\mathbf{1 0 0 \%}$ & $\mathbf{1 . 0 0}$ & $\mathbf{1 4 2 0}$ \\
\hline
\end{tabular}


Core fractional volume was defined for each depletion cycle; for example, Cycle 1 consists of 73 assemblies and thus makes up 38\% of the 193 total assemblies present in a PWR core. The relative assembly power factor $\left(P_{b}\right)$ is the energy output per batch relative to the average energy of all cycles (from a typical Westinghouse PWR). Splitting the entire depletion cycle into even thirds and multiplying the relative assembly factor is what determines the total EFPDs achieved per cycle.

The magnitude of $k_{i n f}$ at 627, 1221, and 1420 EFPD for each fuel geometry and cladding type configuration, as shown in Figure 1, was used to estimate the end-of-cycle (EOC) $\overline{\Delta k}_{\text {core }}$. In doing this, a method similar to the Linear Reactivity Model [11] was developed called the "Equivalent Reactivity Method" [12]. The EOC reactivity for each case was compared to that of a reference case (standard PWR fuel rod with Zircaloy cladding). The core average eigenvalue difference can be estimated using Eq. 1:

$$
\overline{\Delta k}_{\text {core }}=\frac{\sum_{b} x_{b}\left(e_{b}\right) P_{b} V_{b}}{\sum_{b} P_{b} V_{b}} .
$$

In this equation, $x_{b}$ is the difference in infinite multiplication factor between the fuel with alternate cladding and that of the reference case as a function of exposure $\left(e_{b}\right)$. The EOC EFPD values from Table 4 were used to quantify the level of exposure each batch received. The power weighting factor $\left(P_{b}\right)$ approximates the power distribution in the core to provide a measure of contribution of each fuel batch to the overall core reactivity. Finally, the number of assemblies per fuel batch found in a given cycle of a PWR core is denoted by $V_{b}$.

Positive $\overline{\Delta k}_{\text {core }}$ values with respect to the reference case (Case 1 with $4.9 \%$ enriched $\mathrm{UO}_{2}$ in Zircaloy- 4 cladding) are highlighted in Table 5. When the difference is zero, identical cycle lengths to the reference scenario are achieved.

Table 5. Cycle reactivity difference for alternate fuel cladding concepts from the reference PWR fuel with Zircaloy-4 cladding

\begin{tabular}{cccccccc}
\hline Case \# & $\begin{array}{c}\mathbf{U U O}_{2} \\
\text { Volume }\end{array}$ & $\begin{array}{c}{ }^{235} \mathbf{U} \\
\text { Enrichment }\end{array}$ & Specific Power [MW/MTU] & 304SS & 310SS & FeCrAl & \multirow{2}{*}{ APMT } \\
\hline $\mathbf{1}$ (ref) & 0 & $4.9 \%$ & 38.33 & -0.054 & -0.063 & -0.042 & -0.052 \\
$\mathbf{2}$ & $3.5 \%$ & $4.9 \%$ & 37.03 & -0.041 & -0.048 & -0.030 & -0.038 \\
$\mathbf{3}$ & $8.5 \%$ & $4.9 \%$ & 35.31 & -0.023 & -0.029 & -0.014 & -0.021 \\
$\mathbf{4}$ & $13.7 \%$ & $4.9 \%$ & 33.71 & -0.006 & -0.010 & 0.001 & -0.005 \\
$\mathbf{5}$ & 0 & $5.5 \%$ & 38.33 & -0.027 & -0.036 & -0.015 & -0.025 \\
$\mathbf{6}$ & 0 & $6.0 \%$ & 38.33 & -0.006 & -0.015 & 0.006 & -0.004 \\
$\mathbf{7}$ & 0 & $6.5 \%$ & 38.33 & 0.014 & 0.005 & 0.026 & 0.026 \\
$\mathbf{8}$ & 0 & $7.0 \%$ & 0.033 & 0.024 & 0.045 & 0.045 \\
\hline
\end{tabular}




\section{DISCUSSION}

\subsection{ISOTOPIC EVOLUTION IN THE CLADDING}

Evolution of the isotopic cladding composition is of interest since it provides insight with regards to activation of important alloying elements, production of detrimental chemical species, and the radioactivity during operation and upon discharge from the core. The time-dependent isotopics for Zircaloy-4, 304SS, 310SS, and the generic FeCrAl alloy are shown in Figures 3-6. The figures show all isotopes in the system that had a presence of roughly one atomic ppm or greater at end of life (EOL). Several observations are worth noting. In iron-based alloys, $(n, p)$ and $(n, \alpha)$ reactions result in the production of significant amounts of hydrogen and helium in the cladding. In austenitic alloys, the presence of nickel results in hydrogen and helium elemental concentrations roughly an order of magnitude higher compared to ferritic alloys; the absence of nickel also eliminates production of significant amounts of ${ }^{58} \mathrm{Co}$ and ${ }^{60} \mathrm{Co}$ in ferritic alloys. No significant transmutation of any of the initial alloying elements in the cladding is noticeable. This implies that any evolution in performance characteristics of the cladding will be dominated by radiation effects as opposed chemical alterations. The discussion on irradiation effects and operational performance of these alloys is well beyond the scope of this manuscript and is discussed in detail elsewhere [3].

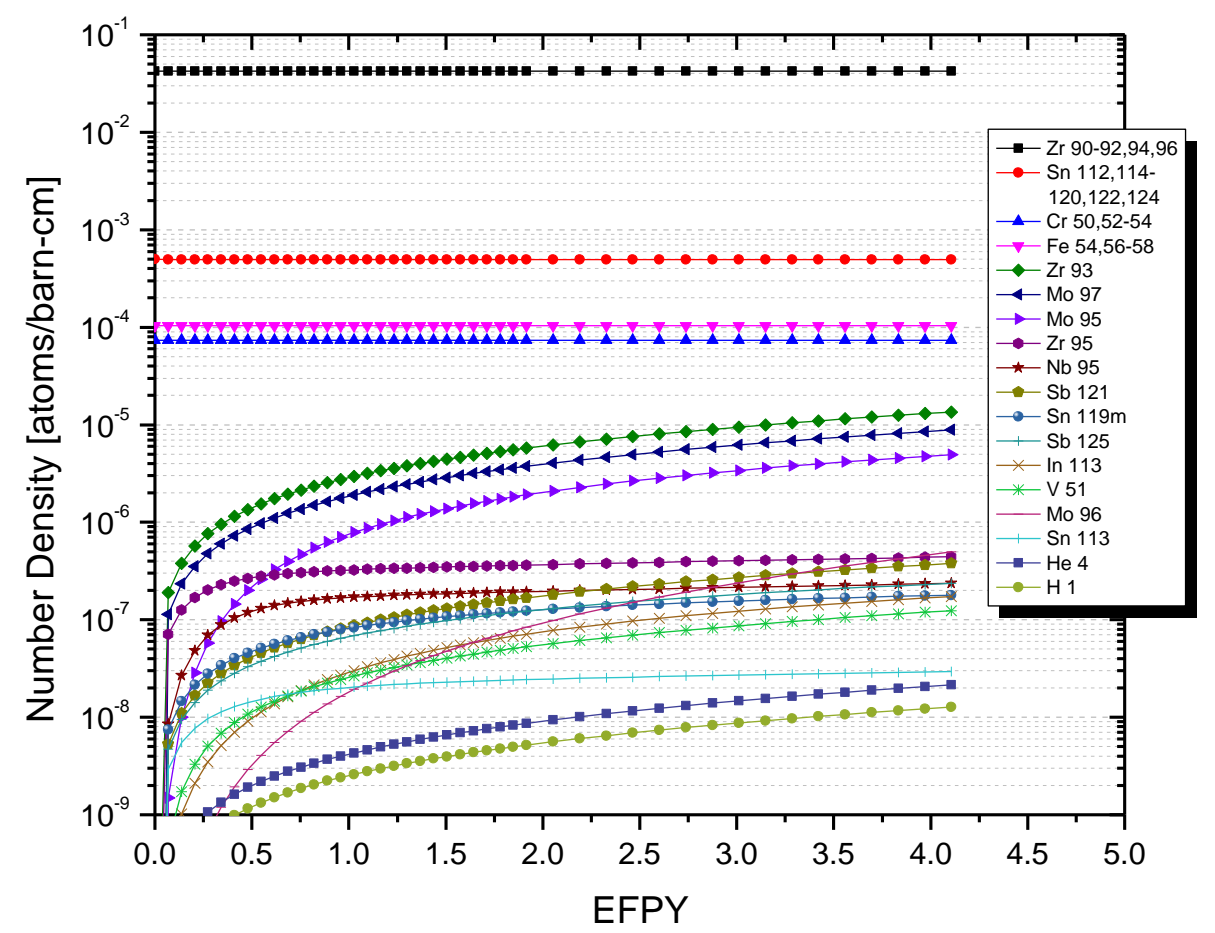

Figure 3. Evolution in isotopic inventory in Zircaloy-4 cladding during fuel lifetime. 


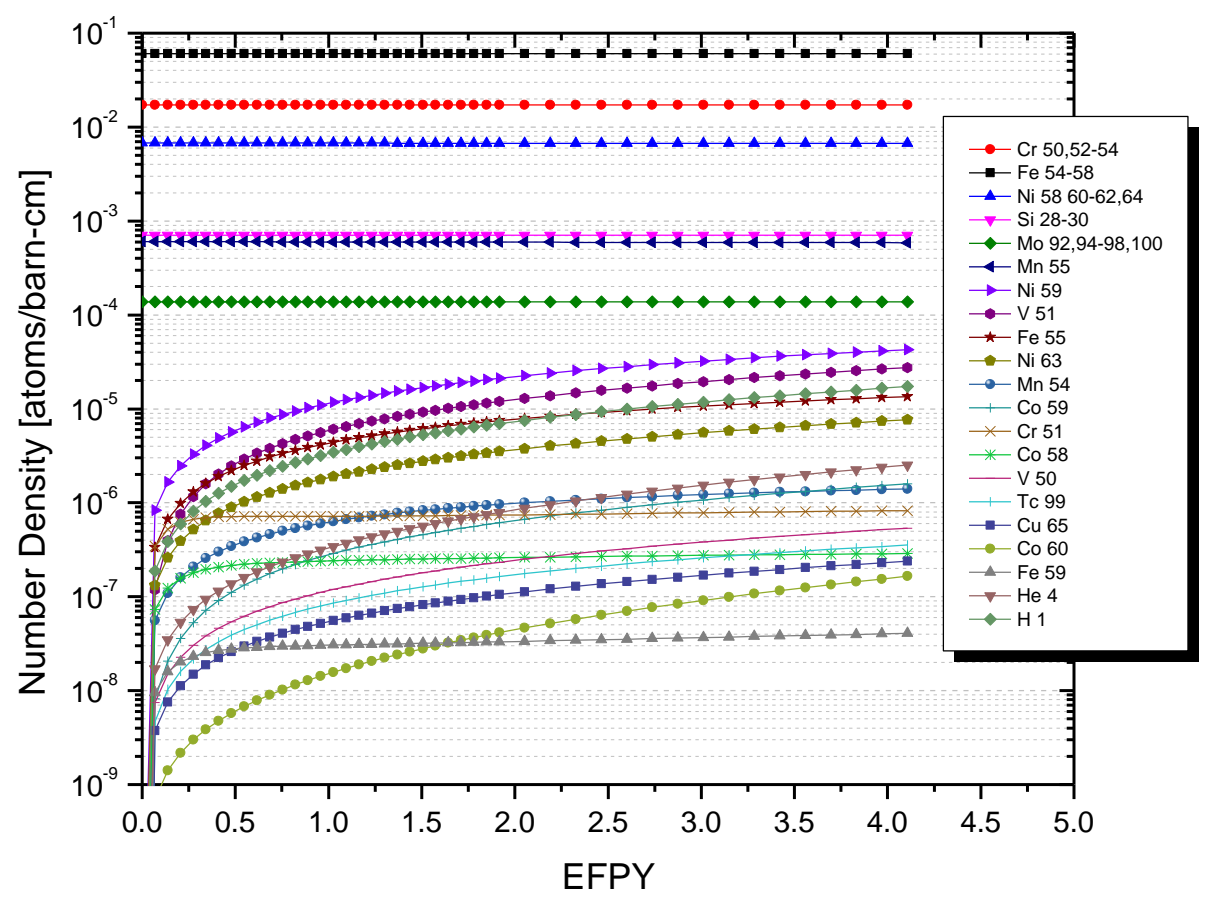

Figure 4. Evolution in isotopic inventory in 304SS cladding during fuel lifetime.

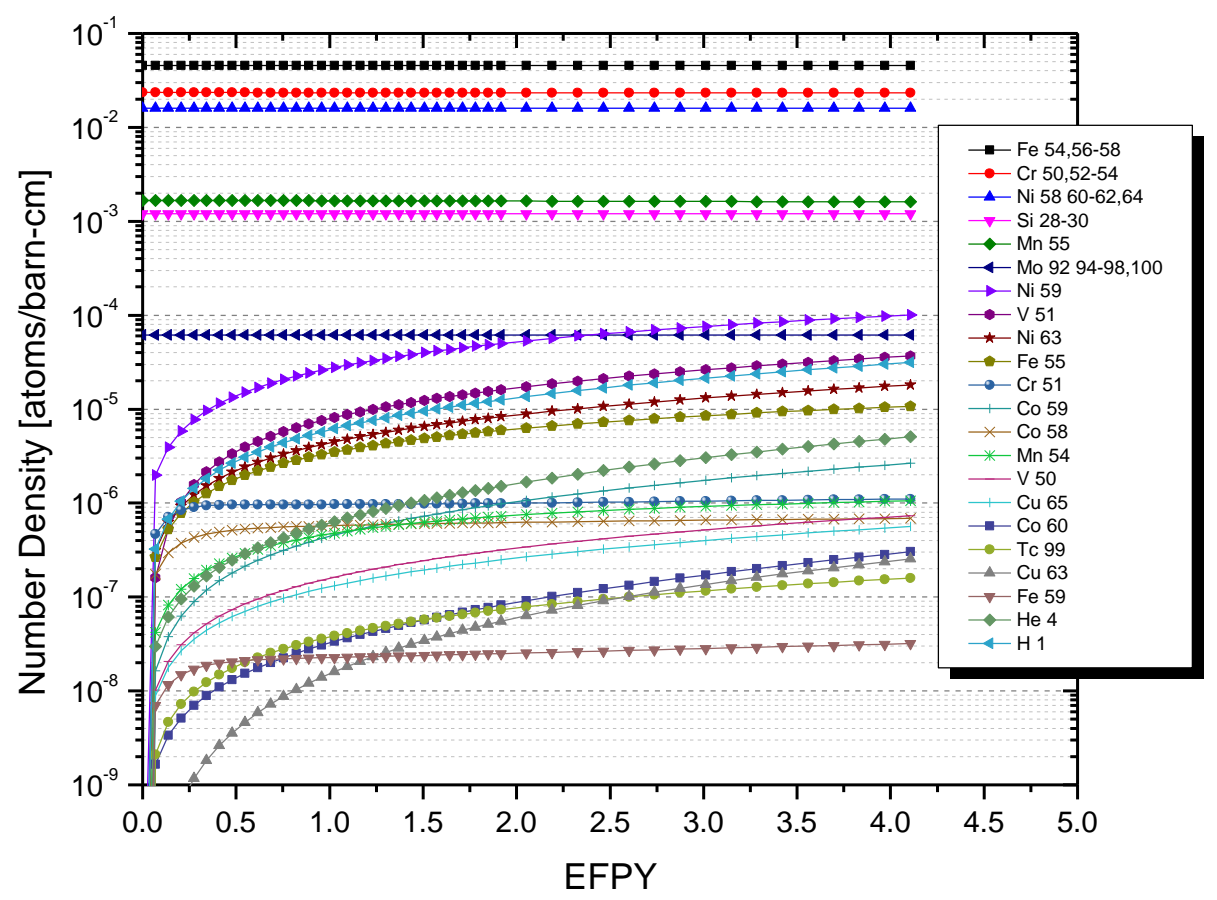

Figure 5. Evolution in isotopic inventory in 310SS cladding during fuel lifetime. 


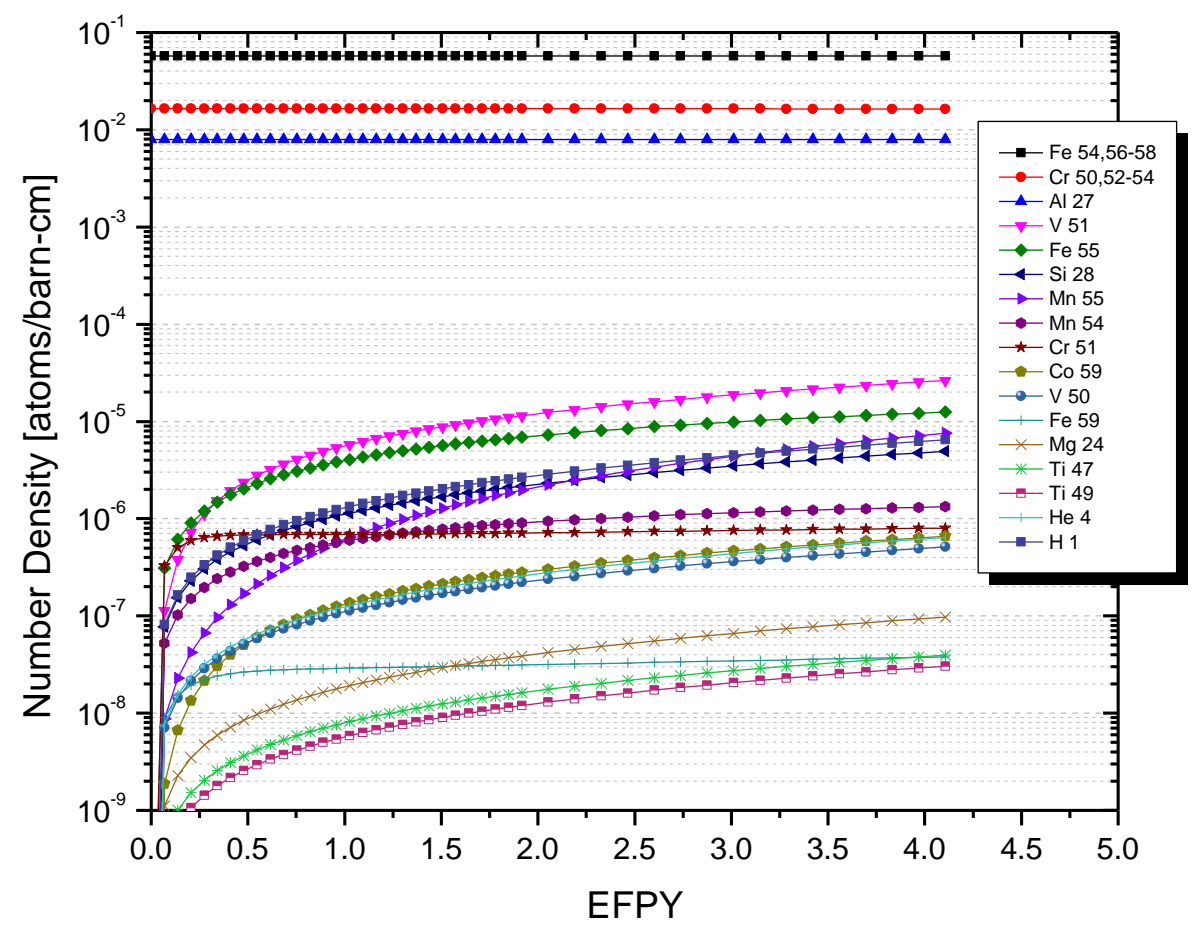

Figure 6. Evolution in isotopic inventory in FeCrAl cladding during fuel lifetime.

\subsection{PLUTONIUM INVENTORY IN FUEL}

Figure 7 shows the total plutonium inventory in the fuel pellets for the reference rod geometry with various cladding materials. Plutonium inventory increases differently over time for the fuel rods with different cladding materials. A common observation is that for the cladding with higher neutron capture cross sections, the EOL plutonium inventory exceeds that of the reference fuel rod with Zircaloy-4 cladding. It is apparent that when using alternative cladding materials, as opposed to Zircaloy, the neutron spectrum hardens. This is because the steel cladding absorbs more thermal neutrons than Zircaloy cladding, and therefore the proportion of fast neutrons in steel-clad systems increases. In turn, this increases the resonance neutron capture in ${ }^{238} \mathrm{U}$, hence generating more plutonium. For this reason, as the depletion cycle continues towards EOC, the deviation in $\mathrm{k}_{\text {inf }}$ between the cases with Zircaloy cladding and steel cladding diminishes slightly. Although there is a reactivity penalty earlier in life due to the high absorbing steel material, some reactivity is gained back later in life with the greater accumulation of plutonium. This trend can be seen in Figures 1 and 2. 


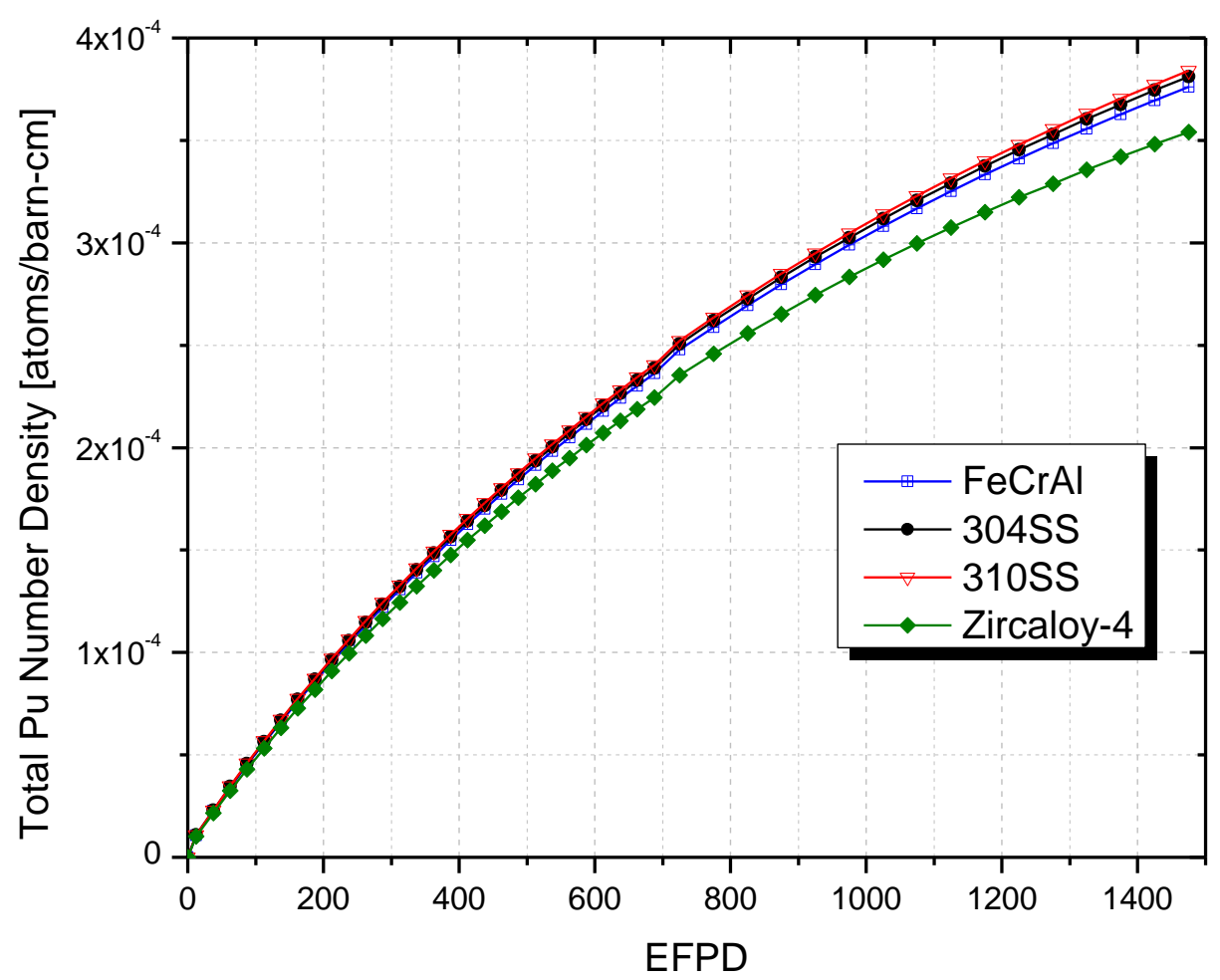

Figure 7. Evolution in plutonium inventory during lifetime with various cladding materials.

\subsection{THERMAL FLUX INVENTORY}

Spectral hardening was investigated further by comparing the three alternate cladding designs from Figure 7 and the reference Zircaloy cladding case. Beginning of life pin cell calculations were performed using Case 1, and the normalized flux spectrum (238 energy groups) was plotted in Figure 8. Specifically, the flux was calculated across a plane perpendicular to the axial direction of the rod at the center height spanning across the entire cell (fuel, cladding, and moderator). As shown in the figure, the cladding designs with higher thermal absorption cross sections cause the neutron spectrum to harden. Zircaloy cladding, having the least absorbing material of the four, contains the highest inventory of thermal neutrons, while FeCrAl, SS-304, and 310SS have a significantly lower inventory of thermal neutrons. This directly correlates to their reactivity penalty found in Figure 2 and plutonium inventory increase in Figure 7. 


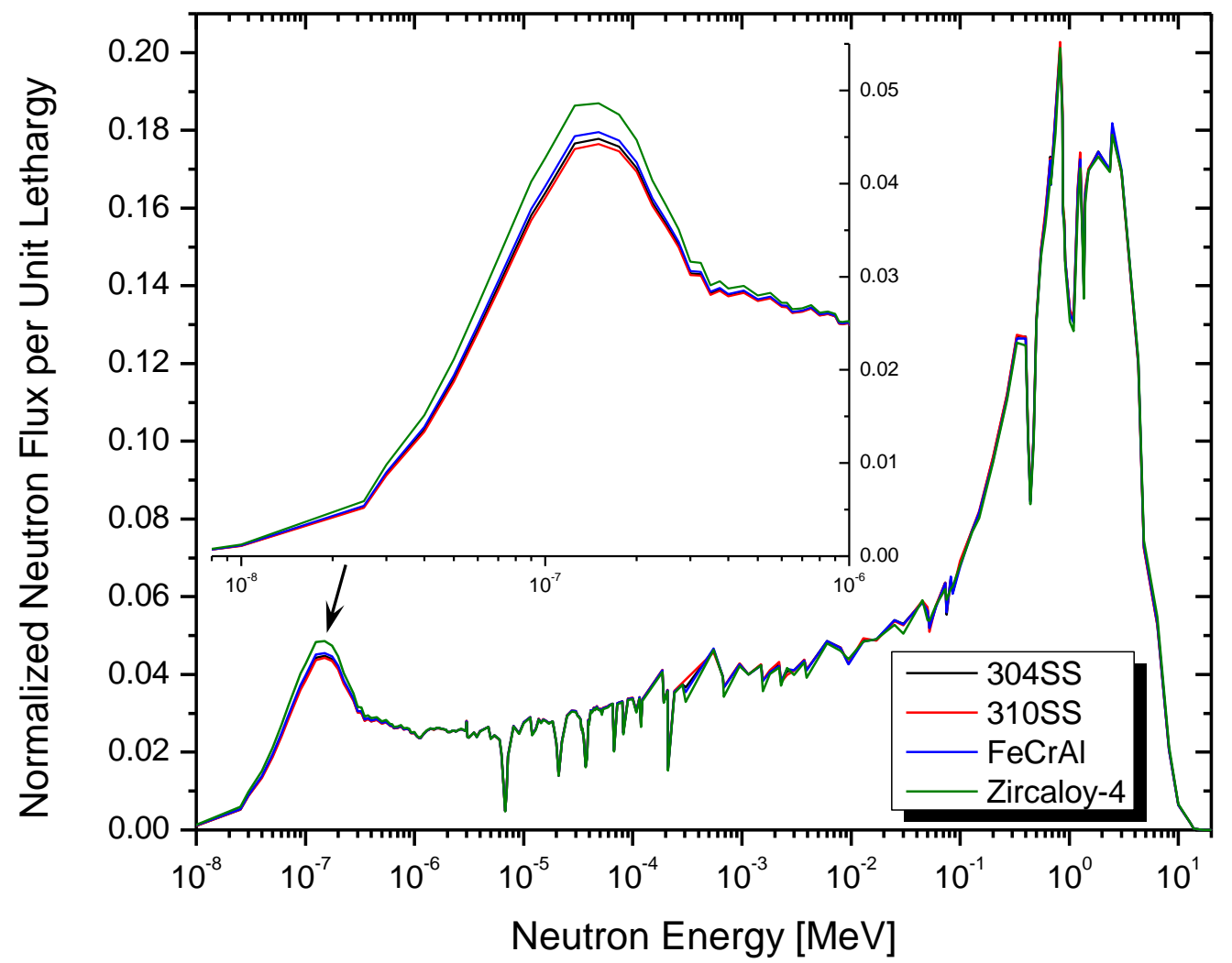

Figure 8. Average scalar flux of various cladding material designs with respect to energy. 


\section{CONCLUSIONS}

The neutronic penalty associated with a transition away from zirconium alloy cladding to iron-based alloy cladding materials for PWR fuel pins was quantified. The penalty in the reference PWR fuel geometry was most noticeable with austenitic stainless steels since they contain nickel as an alloying element. Two routes for increasing core reactivity over the fuel lifetime were examined: increasing the uranium enrichment and increasing fuel pellet diameter at the expense of cladding thickness. For ferritic alloys, a reduction in cladding thickness by roughly half or an increase in enrichment by $\sim 1 \%$ resulted in enhanced core reactivity matching that of reference PWR bundles with Zircaloy cladding. For austenitic alloys that incur a larger neutronic penalty due to presence of nickel, a higher enrichment will be required $(\sim 1.5 \%)$. Spectrum hardening in the fuel in case of alternate fuel cladding concepts with higher thermal neutron capture cross section results in a slight enhancement in plutonium breeding. Fuel rod integrity needs to be reassessed using the rigorous fuel design evaluation process upon any geometry change. Similarly, a full economic analysis of the fuel cycle cost is necessary to examine deployment viability for these alternate fuel concepts.

\section{ACKNOWLEDGMENTS}

The aid and technical insight of Jess Gehin and Andrew Worrall at ORNL are gratefully acknowledged. Useful comments were provided by Brian Ade at ORNL. The work presented in this paper was supported by the Advanced Fuels Campaign of the Fuel Cycle R\&D program in the Office of Nuclear Energy, US Department of Energy. The United States Government retains, and by accepting the article for publication, the publisher acknowledges that the United States Government retains, a non-exclusive, paidup, irrevocable, worldwide license to publish or reproduce the published form of this work, or allow others to do so, for United States Government purposes. 


\section{REFERENCES}

[1] P. Hofmann, Journal of Nuclear Materials 270 (1999) 194.

[2] M. Steinbrück, M. Große, L. Sepold, J. Stuckert, Nuclear Engineering and Design 240 (2010) 1714.

[3] K.A. Terrani, S.J. Zinkle, L.L. Snead, "Advanced Oxidation-Resistant Iron-Based Alloys for LWR Fuel Cladding," submitted, Journal of Nuclear Materials (2013).

[4] B.A. Pint, K.A. Terrani, M.P. Brady, T. Cheng, J.R. Keiser, Journal of Nuclear Materials, in press (2013).

[5] M. Moalem, D.R. Olander, Journal of Nuclear Materials 182 (1991) 170.

[6] M.D. DeHart, S.M. Bowman, Nuclear Technology 174 (2011) 196.

[7] S.M. Bowman, Nuclear Technology 174 (2011) 126.

[8] SCALE: A Comprehensive Modeling and Simulation Suite for Nuclear Safety Analysis and Design, ORNL/TM-2005/39, Version 6.1, Available from Radiation Safety Information Computational Center at Oak Ridge National Laboratory as CCC-785, Oak Ridge, Tennessee, June 2011.

[9] Kanthal APM and APMT Tube Material datasheet, AB Sandvik group, Sandviken, Sweden.

[10] Nuclear Engineering International 49, (Sept. 2004) 26.

[11] M.J. Driscoll, T.J. Downar, E.E. Pilat, The linear reactivity model for nuclear fuel management, American Nuclear Society La Grange Park, Illinois,, USA, 1990.

[12] N.M. George, I. Maldonado, K.A. Terrani, A. Godfrey, J. Gehin, Neutronics studies of uraniumbased fully ceramic micro-encapsulated fuel for PWRs, PHYSOR 2012, Knoxville, Tennessee, USA, April 15-20, 2012. 